\title{
Formulation of an Index for Sea Breezes in Opposing Winds
}

\author{
A. PORSON \\ Institut d'Astronomie et de Géophysique Georges Lemaître, Université catholique de Louvain, Louvain-la-Neuve, Belgium \\ D. G. STEYN \\ Department of Earth and Ocean Sciences, The University of British Columbia, Vancouver, British Columbia, Canada \\ G. SCHAYES \\ Institut d'Astronomie et de Géophysique Georges Lemaître, Université catholique de Louvain, Louvain-la-Neuve, Belgium
}

(Manuscript received 14 July 2006, in final form 21 November 2006)

\begin{abstract}
A scaling analysis is conducted to explore the dependence of sea-breeze speed and inland occurrence in the presence of opposing winds on a set of dynamical parameters. The overall aim of the analysis is to develop an index for sea-breeze occurrence in the face of opposing winds, similar to the Biggs and Graves lake-breeze index. Most studies separate sea-breeze speed and sea-breeze inland occurrence or, at best, link the two in linear analyses. This work analyzes the output of a nonlinear numerical mesoscale model (in idealized simulations) using scaling methods commonly applied in observational studies. It is found that the scaled sea-breeze speed, in response to increasing magnitude of opposing wind, shows two distinct phases: a phase of increasing speed while the sea breeze progresses inland and a phase of sharply decreasing speed when the sea breeze is no longer detected inland. The analysis also allows the development of an index for sea-breeze inland occurrence. This index is an improvement over existing analyses through the use of nonlinear scaling and the use of surface heat flux as opposed to simpler land-sea temperature contrasts.
\end{abstract}

\section{Introduction}

Sea breezes are mesoscale circulations induced by differential heating between sea and land. Opposing winds acting on sea breezes can reduce air quality at coastlines by creating an area of calm winds at the front (Pielke and Segal 1986). Opposing winds can also strengthen vertical velocities at the front (Gilliam et al. 2004) and affect cloud formation and thunderstorm development at coastlines. If too strong, opposing winds can suppress sea breezes (Arritt 1993). The effect of opposing winds on sea-breeze speed and the effect on inland extent have generally been investigated separately, or at best, linked to each other through linear assumptions as developed in the following text. It is therefore interesting to understand fully this link be-

Corresponding author address: A. Porson, Department of Meteorology, University of Reading, P.O. Box 243, RG6 6BB Reading, United Kingdom.

E-mail: a.n.f.porson@reading.ac.uk

DOI: 10.1175/JAM2525.1

(C) 2007 American Meteorological Society tween the two main effects of opposing winds on seabreeze dynamics by conducting a fully nonlinear analysis.

The effect of opposing winds on sea-breeze circulations was first studied by Biggs and Graves (1962), who suggested that the difference between days with or without sea breezes detected at coastlines depends on the nondimensional ratio of the opposing wind speed to the land-sea temperature difference $\varepsilon$ as

$$
\varepsilon=\frac{U^{2}}{C_{p} \Delta T},
$$

with $\Delta T$ defined as the difference between the temperature over land (air temperature) and the temperature over the sea. In the study of Biggs and Graves, the temperature over the sea is the temperature of Lake Erie and the land temperature is the maximum air temperature over a day, measured near the lake shore, with the lake effect removed. Here, in the numerical analysis, the temperature over the sea $T_{\text {sea }}$ will be first considered to lead to neutral static conditions over the sea, 
and the temperature over land $T_{\text {land }}$ is the air temperature interpolated down to $2 \mathrm{~m}$ above ground level. The variable $T_{\text {land }}$ is measured at approximately $50 \mathrm{~km}$ from the coast so that sea effects are not taken into account, and $C_{p}$ is the heat capacity at constant pressure (1003 J $\mathrm{K}^{-1} \mathrm{~kg}^{-1}$ ) and $U$ is the average hourly wind speed selected from synoptic criteria to be offshore.

When this ratio has a value of approximately 3 , the sea breeze is unable to overcome the opposing wind and is no longer detected inland. This ratio was introduced by Biggs and Graves as an index of sea-breeze occurrence. However, Arritt (1993) showed from numerical simulations that opposing winds strong enough to prevent sea-breeze circulations from reaching coastlines do not suppress them directly but rather force them to remain over the sea surface. He found that sea breezes of maximum intensity are those that just reach the coastline, in the face of opposing winds.

A few observational studies confirmed the utility of the Biggs and Graves index, but with different magnitudes than three (Miller et al. 2003). Using observations from the Athens basin, Asimakopoulos et al. (1999) used the Biggs and Graves index to study the speed of sea breezes with opposing winds. The observations showed sea-breeze speed to be linearly related to the Biggs and Graves index but with a large scatter. The differences in magnitude of the critical Biggs and Graves index found in the literature could be attributed to the different methods used to obtain the observations, while their scatter could also be due to the linearity of Biggs and Graves' analysis, and possibly to the presence of unaccounted variables. Walsh (1974) used a linear theory to reproduce the Biggs and Graves index. He realized that the index value is dependent on the eddy conduction coefficient of heat, so that the larger the transfer of heat into the air, the larger the contribution of the thermal force. Laird et al. (2001) also found from climatological data over Lake Michigan during a $15-\mathrm{yr}$ period that although the temperature difference is an important factor for lake-breeze development, their relation to seasonal lake-breeze frequency should be examined further. Based on recent studies of pure sea-breeze speed scaling (Steyn 2003; Wichink Kruit et al. 2004; Tijm et al. 1999; Porson et al. 2007a), this analysis of Walsh suggests that the index should be reformulated so as to incorporate surface heat flux, rather than land-sea temperature difference.

Here we will use idealized 2D numerical simulations subjected to scaling analysis from Porson et al. 2007a in order to connect the Biggs and Graves index to the speed scaling of pure sea breezes based on surface heat flux. This is similar to the approach taken by Tijm (1999) but with the additional linearization that when sea breezes just reach the coastline, their speed is equal to the magnitude of the opposing synoptic wind. The numerical model used for this study is the topographic vorticity mesoscale model (TVM), a vorticity-component model fully described in Schayes et al. (1996) and in Thunis and Clappier (2000).

The research questions are the following:

1) Can the numerical model be used to represent the influence of opposing winds on the change of inland extent of sea breezes?

2) What is the influence of opposing winds on seabreeze scaling? Can we relate this influence to the position of the sea-breeze circulation inland or over the sea surface?

3) Can the speed scaling be used to derive a new expression similar to the Biggs and Graves index?

4) Does this new formulation improve on the performance of the Biggs and Graves index?

\section{Sea-breeze scaling and offshore winds}

Following Porson et al. (2007a,b), we use the nonlinear numerical model atmospheric TVM, which is a meso- $\gamma$-scale atmospheric model. Prognostic variables are potential temperature, turbulent kinetic energy, and two horizontal vorticity components. The calculation of vorticity components avoids integration of the dynamical pressure and air density. In this model, the surface temperature evolves using the force-restore soil model of Deardoff (1978). A (dry) nonsaturated atmosphere is assumed, infrared absorption by water vapor is neglected in the model, a constant geostrophic wind forcing in the offshore direction is applied through the atmosphere, and the nonhydrostatic and anelastic version is used. A numerical diffusion filter for high spatial wavenumbers was employed to avoid perturbations triggered by convection (Raymond and Garder 1988), and this proved to be more efficient than a higher and constant horizontal diffusion coefficient (Arritt 1989). The model employs a 1.5-order turbulence scheme and uses the mixing length formulation of Bougeault and Lacarrère (1989). TVM will be operated in two dimensions in a vertical plane along the west-east direction, which is perpendicular to the shoreline. Referring to the different controls on sea-breeze inland penetration in Miller et al. (2003), the 2D setting implies that the study is simplified in respect to coastline curvature (here taken to be straight), ambient stability (same over sea as over land), and to the interaction with other mesoscale systems (as lake breeze or orography). However, the scaling analysis conducted here derives from the observations of Steyn (2003) for which coastline 
curvature and other mesoscale circulations might not have been negligible. The modification by topography was numerically studied in Porson et al. (2007b).

\section{a. Model comparison with the literature}

To ensure that TVM is capable of capturing the influence of opposing winds on the inland extent of sea breezes, let us compare the results of TVM with observations reported in Finkele (1998). Based on 3D model runs and aircraft measurements, Finkele (1998) observed three cases of sea breezes during offshore wind conditions of $-2.5,-5$, and $-7.5 \mathrm{~m} \mathrm{~s}^{-1}$. For the speed of $-2.5 \mathrm{~m} \mathrm{~s}^{-1}$, she deduced that inland propagation of the sea breeze occurs at almost a constant and low speed from 1045 local solar time (LST) (when the sea breeze reaches the coastline) until 1500 LST, after which time the circulation accelerates its inland movement. This almost stationary behavior of sea-breeze inland propagation speed was justified by Physick (1980) in zero synoptic gradients: when sea breezes propagate inland, the marine air behind the front over land is modified by contact with the surface (through surface heat flux) so that the density difference between seabreeze air and air ahead of the front is reduced. This behavior prevails until late afternoon when the surface heat flux decreases and allows the density difference to rebuild. For the second case of $-5 \mathrm{~m} \mathrm{~s}^{-1}$, Finkele observed that the sea-breeze circulation reached the coastline later (1330 LST), after which time the seabreeze circulation slowed down. For the third case, she observed that the sea-breeze circulation remained completely offshore.

Figure 1 shows the sea-breeze inland progression of the maximum vertical velocity modeled by TVM as a function of time (LST) for various offshore geostrophic wind speeds (as developed later in this section, the position of the maximum vertical speed is used as an indicator of the sea-breeze front and thus of the horizontal extent of the circulation). The rapid inland progression in late afternoon is effectively reproduced for the lowest wind speed of $-2.5 \mathrm{~m} \mathrm{~s}^{-1}$, while the inland progression appears to be slowed down for the moderate geostrophic wind speeds of $-5 \mathrm{~m} \mathrm{~s}^{-1}$. Finally, the strongest geostrophic wind speed forces the sea breeze to remain offshore after the onset phase. For $-6 \mathrm{~m} \mathrm{~s}^{-1}$, the circulation is, for most of its lifetime, over the sea and only reaches the coast in late afternoon. For a speed of $-7.5 \mathrm{~m} \mathrm{~s}^{-1}$, the entire sea-breeze cell remains over the sea surface.

From this analysis, it appears that TVM is capable of capturing the effect of offshore winds on sea-breeze inland position. The next step is to investigate how opposing winds affect the sea-breeze scaling, that is, how

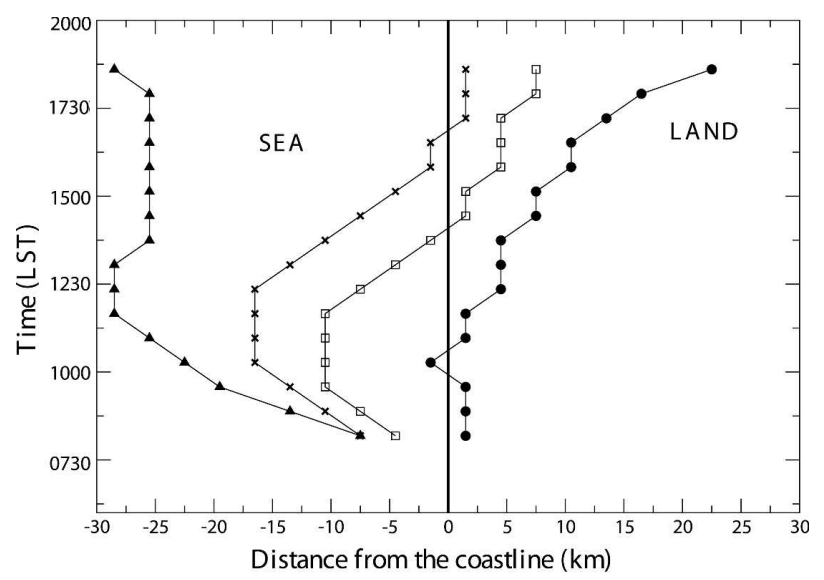

FIG. 1. Sea-breeze inland progression (the actual position of the front, where vertical velocity reaches a maximum) as a function of time (LST). A low-wind-speed case of $-2.5 \mathrm{~m} \mathrm{~s}^{-1}$ is illustrated with circles. Two moderate cases of -5 and $-6 \mathrm{~m} \mathrm{~s}^{-1}$ are depicted with squares and crosses, respectively. A strong-wind case of -7.5 $\mathrm{m} \mathrm{s}^{-1}$ is represented with triangles.

opposing winds affect the relative roles of properties that control sea-breeze propagation through scaling analysis. Sea-breeze scaling from the most recent studies (Tijm et al. 1999; Steyn 2003; Wichink Kruit et al. 2004; Porson et al. 2007a) shows that sea-breeze speed with no large-scale wind forcing obeys the velocity scaling law:

$$
u_{\text {sbscale }}=\left(\frac{g H}{T \omega}\right)^{1 / 2} \text {, }
$$

where $H$ is the time-averaged integrated surface heat flux since sunrise measured near coastline, $g / T$ is the buoyancy parameter, and $\omega$ is the earth's diurnal rotation frequency. The Coriolis parameter $f$ does not appear in Eq. (2) because the scaling collapses at the equator (Steyn 2003) and because the latitude dependence is implicitly embedded in the surface heat flux dependence. The $\omega$ parameter derives from the linear theory of sea breezes (Steyn 1998). Following Porson et al. (2007a), the mean sea-breeze speed (averaged over sea-breeze depth) is scaled as $0.3 u_{\text {sbscale }}$ at $49^{\circ} \mathrm{N}$, the latitude of Vancouver, Canada [referring to Steyn (2003), for another latitude other than $49^{\circ}, 0.3$ becomes $0.85 \Pi_{2}^{-9 / 4}$ with the nondimensional group $\left.\Pi_{2}=f / \omega\right]$. To investigate the effect of opposing winds on this scaling, a set of numerical simulations was run with different initial conditions of opposing geostrophic winds $U_{g}$ to $-8 \mathrm{~m} \mathrm{~s}^{-1}$ and ambient stability (vertical potential temperature gradient $\gamma$ ) in 10 stability values as defined from Eq. (3):

$$
\gamma_{i}=1.65+0.5 i \mathrm{~K} \mathrm{~km}^{-1} \text { and } i=0,9 \text {. }
$$




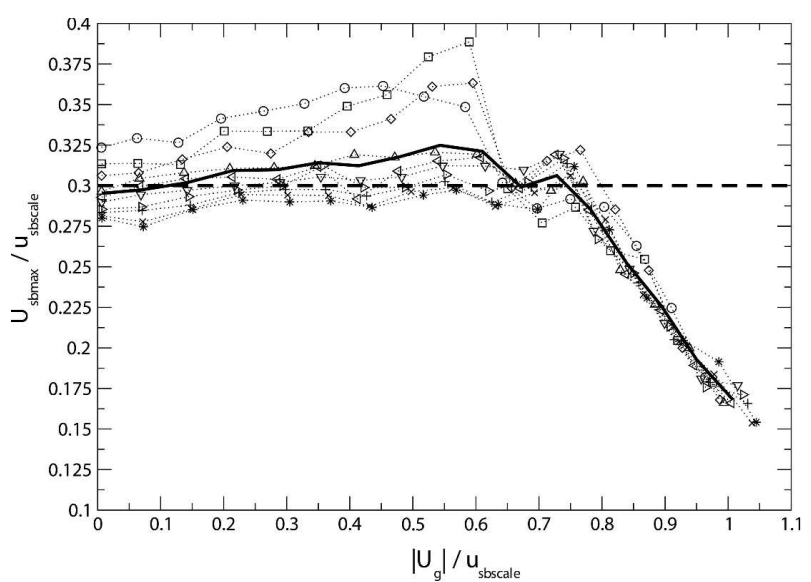

FIG. 2. Model outputs of $\left(U_{\text {sbmax }} / u_{\text {sbscale }}\right)$ vs the geostrophic wind speed $\left(\left|U_{g}\right| / u_{\text {sbscale }}\right)$. The 10 groups of stability $\gamma_{i}$ are illustrated by different symbols ( $\gamma_{1}$ with open circles, $\gamma_{2}$ with squares, $\gamma_{3}$ with diamonds, $\gamma_{4}$ with triangles up, $\gamma_{5}$ with triangles left, $\gamma_{6}$ with triangles down, $\gamma_{7}$ with triangles right, $\gamma_{8}$ with pluses, $\gamma_{9}$ with crosses, and $\gamma_{10}$ with stars). The average of these 10 groups is represented by the black solid line. The black dashed line depicts the pure sea-breeze regime $\left(U_{g}=0\right)$.

\section{b. Scaling of the absolute speed}

We extract the maximum of the vertically averaged horizontal sea-breeze speed in the range from $6 \mathrm{~km}$ inland to $-60 \mathrm{~km}$ over the sea surface $U_{\text {sbmax }}$ as

$$
U_{\mathrm{sbmax}}=\max \left[\frac{1}{Z_{\mathrm{sb}_{i}}} \int_{0}^{Z_{\mathrm{sb}_{i}}} U_{i}(z) d z\right]_{i=-60,+6 \mathrm{~km}},
$$

where $Z_{\mathbf{s b}_{i}}$ is the sea-breeze depth at location $i$ and $U_{i}(z)$ is the horizontal wind component of the seabreeze circulation at location $i$ and height $z$. The maximum sea-breeze scaled speed $U_{\text {sbmax }} / u_{\text {sbscale }}$ shows two regimes that are distinguished by a scaled opposing wind speed of magnitude $\left|U_{g}\right| / u_{\text {sbscale }}$ of $0.65-0.75$ as shown in Fig. 2. The difference between the two regimes lies in the inland position of the sea-breeze circulation: in the second regime, the sea-breeze circulation does not reach the coastline and its speed progressively decreases. This second regime shows less scatter than is evident in the first.

The mechanisms of the first regime are quite complex: two competing effects control the circulation and explain the larger scatter of the different stability groups. These two effects are mentioned in the literature as first, a feedback between surface wind convergence and horizontal potential temperature gradient at the sea-breeze front resulting in an increase of the intensity of the thermally induced speed of the sea-breeze circulation (Arritt 1993) and second, the friction force at the front resulting in a decrease of sea-breeze speed [see the gravity current study of Simpson and Britter (1980)]. Arritt (1993) showed that when we add the magnitude of the opposing wind to the absolute seabreeze speed, we find that the resulting speed perturbation from the imposed large-scale flow increases with an increase in magnitude of the opposing wind. This feedback effect (that links sea-breeze speed to surface wind convergence) is dependent on ambient stability via the updraft velocities at the front, which explains why strong stability cases (for which updraft velocities are inhibited) are almost insensitive to opposing winds in this first phase (see Fig. 2). This comment can justify the scatter in the observations of Asimakopoulos et al. (1999) as mentioned in the introduction.

Figure 2 illustrates that sea-breeze scaling with opposing winds and the corresponding two regimes are strongly related to sea-breeze inland occurrence. This gives us confidence that sea-breeze inland occurrence can be studied with the surface heat flux $H$ [included in the velocity scale $u_{\text {sbscale }}$ in Eq. (2), as in the next section].

\section{Formulation of an index}

We will focus now on the dependence of the critical opposing speed $U_{\text {gcrit }}$ (for which the sea-breeze circulation does not reach the coastline) on the velocity scale $u_{\text {sbscale }}$. The surface heat flux parameter $H$ measured near coastline used in $u_{\text {sbscale }}$ [Eq. (2)] allows us not only to take into account the vertical heat transfer into the air column [rather than the land-sea temperature difference $\Delta T$ used in the index of Biggs and Graves and defined in section 1; see Pielke and Segal (1986) and Porson et al. (2007a)] but also to capture the dependence of reduced sea-breeze speed and instability production on sea surface temperature (Arritt 1987).

To derive an index of sea-breeze occurrence, the criterion used for measuring the critical opposing speed in different cases relies on the position of the maximum of updraft velocity, which indicates roughly the position of the sea-breeze front. More specifically, if, for a given geostrophic speed $U_{g}$, the maximum of the vertical velocity profile still appears over land and, for a given $U_{g}+d U$ (the numerical analysis will use $d U$ equal to $0.1 \mathrm{~m} \mathrm{~s}^{-1}$ ), the maximum of the vertical velocity profile appears over sea, the critical large-scale wind speed will be equal to $U_{g}$.

To focus on the contribution of surface heating, we modify initial conditions by the use of different values of incoming radiation through an artificial cloud layer in TVM. In Fig. 3, $U_{\text {gcrit }}$ is plotted as a function of the velocity scale $u_{\text {sbscale }}$ for different sea surface temperatures; the linear regression when sea surface tempera- 


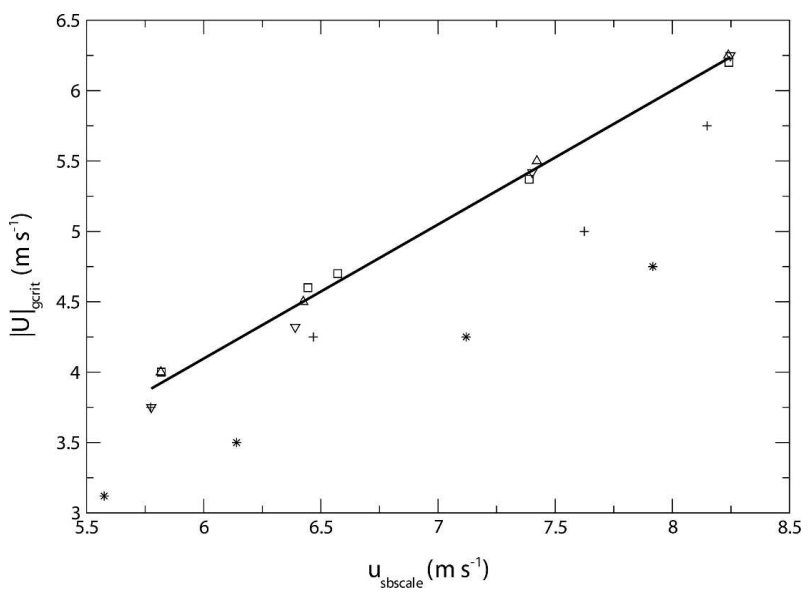

FIG. 3. Dependence of the critical geostrophic wind speed on $u_{\text {sbscale }}$. Different SST configurations are illustrated by the various shapes: the stable classes are depicted by up triangles $(289 \mathrm{~K})$ and down triangles ( $291 \mathrm{~K})$; the neutral class $(293 \mathrm{~K})$ is depicted by the squares; the unstable class is depicted by the plus signs (295 K) and by the stars $(297 \mathrm{~K})$.

ture yields stable or neutral stability over the sea surface is

$$
U_{\text {gcrit }}=-1.6+0.953 u_{\text {sbscale }} \text {. }
$$

The standard deviations to the intercept and coefficient are, respectively, 0.17 and 0.0242 . The case of unstable conditions will be examined shortly. The presence of an intercept different from 0 in Eq. (5) can be interpreted as representing a minimum level of heating required to produce a sea-breeze circulation. If the time-averaged integrated heat flux $H$ is too low, the sea breeze cannot develop and consequently there is no critical wind speed. In these conditions, we can define a minimum of sea-breeze circulation given by a minimum velocity scale $u_{\text {usbscale }_{\min }}$ :

$$
u_{\text {usbscale }_{\min }}=\frac{1.6}{0.953} \approx 1.7 \text {. }
$$

To derive a sea-breeze index from Eq. (5), the equation has to be made dimensionless and is therefore divided by the velocity scale $u_{\text {sbscale }}$, which yields

$$
\frac{U_{\text {gcrit }}}{u_{\text {sbscale }}}=0.953+\frac{-1.6}{u_{\text {sbscale }}}
$$

or

$$
\frac{U_{\text {gcrit }}}{0.953 u_{\text {sbscale }}}=1-\frac{1.6}{0.953 \overline{u_{\text {sbscale }}}},
$$

where $\overline{u_{\text {sbscale }}}$ is typical of the observed conditions and is therefore dependent on the location. In Porson et al. (2007a), numerical simulations were carried out with
TVM to reproduce the scaling analysis of sea breezes over Vancouver by varying the vertical gradient of potential temperature $\gamma$ from 1.65 to $6.15 \mathrm{~K} \mathrm{~km}^{-1}$ (similar to what is done here). Following this range in $\gamma$, a representative value of $\overline{u_{\text {sbscale }}}$ can be derived by using a $\gamma$ value of $3.65 \mathrm{~K} \mathrm{~km}^{-1}$. In this condition, $\overline{u_{\text {sbscale }}}$ is estimated to $8.28 \mathrm{~m} \mathrm{~s}^{-1}$ for a time-averaged integrated surface kinematic heat flux $H$ of $0.15 \mathrm{~m} \mathrm{~K} \mathrm{~s}^{-1}$ and a temperature value of the mixed boundary layer $T$ of $295 \mathrm{~K}$.

A new form for an index of sea-breeze inland occurrence $I_{\mathrm{sb}}$, for stable or neutral conditions, can then be derived from Eqs. (6) and (8):

$$
I_{\mathrm{sb}}=\frac{U_{\text {gcrit }}}{0.953 u_{\text {sbscale }_{\text {sele }}}}=1-\frac{u_{\text {sbscale }_{\text {min }}}}{\overline{u_{\text {sbscale }_{\text {e }}}}},
$$

where $\overline{u_{\text {sbscale }}}$ depends on the location (a representative value of $8.28 \mathrm{~m} \mathrm{~s}^{-1}$ was here obtained for a vertical gradient of potential temperature close to standard atmosphere conditions) and where $u_{\text {sbscale }_{\min }}$ is universal because of its derivation from scaling analysis. Equation (9) can be interpreted as follows for a given opposing geostrophic wind speed $U_{g}$ :

- When $I_{\mathrm{sb}}>0$ or $\left(\overline{u_{\text {sbscale }}} / u_{\text {sbscale }_{\text {min }}}\right)>1$, for which a sea-breeze circulation occurs.

- When $I_{\mathrm{sb}}\left(U_{g}\right)>1-\left(u_{\text {sbscal }_{\min }} \sqrt{u_{\text {sbscale }}}\right)$, for which the sea breeze does not reach the coastline. In this case, the sea-breeze speed will be submitted to a strong decrease as shown in section 2 .

When sea surface temperature creates instability over the sea surface (it is, e.g., the case with sea surface temperatures of 295 and $297 \mathrm{~K}$ used in Fig. 3), the magnitude of the intercept in Eq. (5) becomes larger, which suggests higher minimum levels of the integrated heat flux $H$ to drive a sea-breeze circulation. This behavior is in agreement with Arritt (1987) who obtained smaller sea-breeze speeds in unstable stratification over the sea surface.

The collapse of the neutral and stable stratifications into one line as shown in Fig. 3 and developed from Eqs. (5)-(9) is a substantial improvement over the index of Biggs and Graves as discussed now. Laird et al. (2001) already mentioned that when stable conditions appear over the water, the lake breeze becomes nearly insensitive to the water temperature (or to the temperature difference) because further cooling of the water does not imply further cooling of the atmosphere above the water surface. This is due to increased static stability in the lowest atmospheric layers over the sea, which inhibits mixing and heat transfer. Let us examine from our simulations what this particular behavior of the seabreeze circulation under stable conditions implies for 

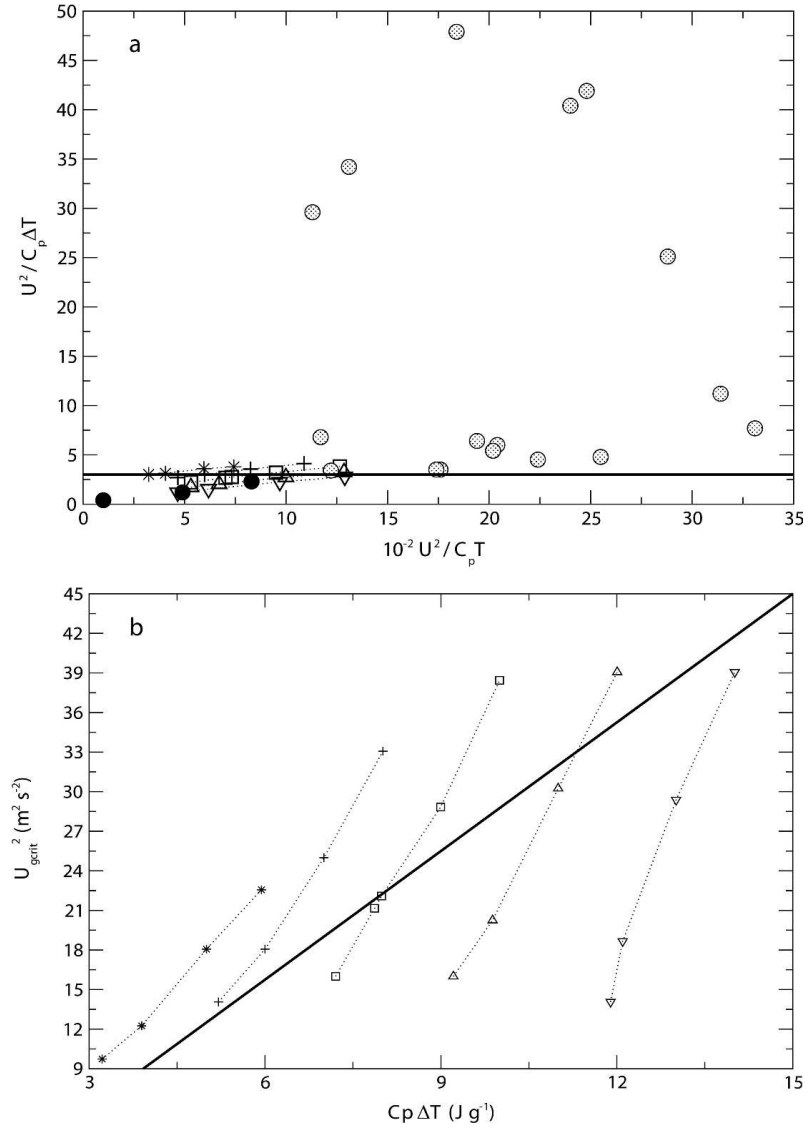

FIG. 4. (a) TVM data and observations from Biggs and Graves (1962) for May 1957 of $\left[10^{-2}\left(U^{2} / C_{p} T\right),\left(U^{2} / C_{p} \Delta T\right)\right]$. The observations are depicted in circles: filled circles show days with a lake-breeze event (days with frontal passage or onshore winds were omitted) and shaded circles show days without a lake-breeze event. The simulations are represented with dashed lines for different SST configurations: the stable class is depicted by the triangles (down triangles for $289 \mathrm{~K}$ and up triangles for $291 \mathrm{~K}$ ), the neutral class $(293 \mathrm{~K})$ is depicted by the squares, and the unstable class is depicted by the plus signs (295 K) and the stars (297 K). The black line is the line $y=3$ where 3 is the value of the nondimensional index from Biggs and Graves (1962). (b) TVM data of $\left(C_{p} \Delta T, U_{\text {gcrit }}^{2}\right)$. The outputs for different SST configurations are illustrated with the same symbols as in (a). The black line here is the line $y=3 x$.

the performance of the index from Biggs and Graves (1962). Biggs and Graves (1962) worked with the landsea temperature difference $\Delta \mathrm{T}$ as mentioned previously. Figure $4 \mathrm{a}$ represents both the observations from Table 3 in Biggs and Graves (1962) and the numerical outputs in the nondimensional space

$$
\left(10^{-2} \frac{U^{2}}{C_{p} T}, \frac{U^{2}}{C_{p} \Delta T}\right)
$$

By plotting their data in this representation, Biggs and Graves (1962) found that days with a lake-breeze cir- culation were located above the line $y=3$ and that days without lake-breeze events were located below the same line. From this, a critical index value of 3 is deduced. Figure $4 \mathrm{a}$ is useful to show how the simulations produced here fit within the observations collected by Biggs and Graves (1962). They classified their data between days with and without sea breezes so that their data are largely spread, while, here, the simulations were conducted to investigate further what is happening at the critical wind speed. Our simulations are therefore confined around the line $y=3$, which makes it difficult, from Fig. 4a, to interpret the comparison between the simulations and the observations. Figure $4 \mathrm{~b}$ is then shown to focus further on this comparison and, subsequently, to emphasize the improvement of the sea-breeze index in Eq. (8) compared to the index from Biggs and Graves (1962). Figure 4b reproduces the simulations in the dimensional space $\left(C_{p} \Delta T, U_{g \text { crit }}^{2}\right)$ so that the index value is the slope of the line $y=3 x$. On this dimensional representation, any deviation between the simulations for different SST and the index value of 3 from Biggs and Graves (1962) can be detected by any difference in slope coefficient from the line $y=3 x$. In Fig. 4b, the sea surface temperatures that lead to atmospheric instability ( 295 and $297 \mathrm{~K}$ ) result in a slope coefficient closer to 3 than found for the sea surface temperatures that lead to stable conditions (293, 291, and $289 \mathrm{~K})$. The latter cases show a systematic dependence on $\Delta T$, which was not the case for Eq. (5). In addition, this result could hint at a particular characteristic of the Biggs and Graves index related to the fact that this index was obtained for a lake breeze and not a sea breeze. If the sea surface temperatures that lead to instability over the sea surface result in a slope coefficient closer to the index of Biggs and Graves than the ones that lead to stability, this might be due to the fact that the water surface in Biggs and Graves (1962) is a lake and that lake surface temperatures are subject, depending on their depth, to larger and more rapid diurnal variations than sea surface temperatures. Alternately, this could justify why other studies carried out over sea surface obtained a larger slope coefficient (Miller et al. 2003).

\section{Conclusions}

This work established a link between sea-breeze speed and sea-breeze inland occurrence in the presence of opposing winds. The scaled speed in opposing wind conditions occurs in two distinct regimes with highly different mechanisms as previously reported in the literature. The first regime relies on the opposing effects of a positive feedback interaction (between surface 
wind convergence, horizontal potential temperature gradient, and vertical velocity at the front) and with the negative friction/mechanical effect at the front. The second regime is characterized by a seaward shift of the sea-breeze circulation. Because of these different mechanisms, this link cannot be understood from linear assumptions on sea-breeze speed in relation to opposing wind speed. Alternately, sea-breeze speed scaling is not linearly affected by opposing winds and thus cannot be interpreted as linear function of the Biggs and Graves index.

In addition, this index was revisited to include surface heat flux instead of land-sea temperature difference as in Biggs and Graves (1962). From this analysis, it is evident that sea breezes will occur if surface heating is above a threshold value. In addition, for a given opposing geostrophic wind, there exists a different threshold value for sea breezes to penetrate inland. The use of surface heat flux allows us to collapse the sea surface temperatures that lead to stable stratifications over the sea surface, a feature not possible in the Biggs and Graves index.

Acknowledgments. This study was supported by FRIA (Fonds pour la formation à Recherche dans l'Industrie et dans l'Agriculture, Belgium), NSERC (Natural Science and Engineering Research Council of Canada), FNRS (Belgian National Fund for Research), and the French Community of Belgium.

Thanks are given to Alberto Martilli and Bruce Ainslie for valuable discussions.

\section{REFERENCES}

Arritt, R., 1987: The effect of water surface temperature on lake breezes and thermal internal boundary layers. Bound.-Layer Meteor., 40, 101-125.

_- 1989: Numerical modelling on the offshore extent of sea breezes. Quart. J. Roy. Meteor. Soc., 115, 547-570.

_ 1993: Effects of the large-scale flow on characteristic features of the sea breeze. J. Appl. Meteor., 32, 116-125.

Asimakopoulos, D. N., C. G. Helmis, K. H. Papadopoulos, J. A. Kalgiros, P. Kassomenos, and M. Petrakis, 1999: Inland propagation of sea breeze under offshore wind. Meteor. Atmos. Phys., 70, 97-110.

Biggs, W. G., and M. E. Graves, 1962: A lake breeze index. $J$. Appl. Meteor., 1, 474-480.

Bougeault, P., and P. Lacarrère, 1989: Parameterization of orog- raphy-induced turbulence in a mesobeta-scale model. Mon. Wea. Rev., 117, 1872-1890.

Deardoff, J., 1978: Efficient prediction of ground surface temperature and moisture, with inclusion of a layer of vegetation. $J$. Geophys. Res., 83, 1889-1904.

Finkele, K., 1998: Inland offshore propagation speeds of a sea breeze from simulations and measurements. Bound.-Layer Meteor., 87, 307-329.

Gilliam, R. C., S. Raman, and D. D. S. Niyogi, 2004: Observational and numerical study on the influence of large-scale flow direction and coastline shape on sea-breeze evolution. Bound.-Layer Meteor., 111, 275-300.

Laird, N., D. A. R. Kristovich, X.-Z. Liang, R. W. Arritt, and K. Labas, 2001: Lake Michigan lake breezes: Climatology, local forcing, and synoptic environment. J. Appl. Meteor., 40, 409424.

Miller, S. T. K., B. D. Keim, R. W. Talbot, and H. Mao, 2003: Sea breeze: Structure, forecasting, and impacts. Rev. Geophys., 41, 1011, doi:10.1029/2003RG000124.

Physick, W. L., 1980: Numerical experiments on the inland penetration of the sea breeze. Quart. J. Roy. Meteor. Soc., 106, 735-746.

Pielke, R. A., and M. Segal, 1986: Mesoscale circulations forced by differential terrain heating. Mesoscale Meteorology and Forecasting, P. S. Ray, Ed., Amer. Meteor. Soc., 516-548.

Porson, A., D. G. Steyn, and G. Schayes, 2007a: Sea-breeze scaling from numerical model simulations, Part I: Pure sea breezes. Bound.-Layer Meteor., 122, 17-29.

,-- , and $-2007 \mathrm{~b}$ : Sea-breeze scaling from numerical model simulations, Part II: Interaction between sea breezes and slope flows. Bound.-Layer Meteor., 122, 31-41.

Raymond, W. H., and A. Garder, 1988: A spatial filter for use in finite area calculations. Mon. Wea. Rev., 116, 209-222.

Schayes, G., P. Thunis, and R. Bornstein, 1996: Topographic vorticity-mode mesoscale- $\beta$ (TVM) model. Part I: Formulation. J. Appl. Meteor., 35, 1815-1823.

Simpson, J. E., and R. E. Britter, 1980: A laboratory model of an atmospheric mesofront. Quart. J. Roy. Meteor. Soc., 106, 485500.

Steyn, D. G., 1998: Scaling the vertical structure of sea breezes. Bound.-Layer Meteor., 86, 505-524.

, 2003: Scaling the vertical structure of sea breezes revisited. Bound.-Layer Meteor., 107, 177-188.

Thunis, P., and A. Clappier, 2000: Formulation and evaluation of a nonhydrostatic mesoscale vorticity model (TVM). Mon. Wea. Rev., 128, 3236-3251.

Tijm, A. B. C., 1999: Sea-breeze studies. Ph.D. thesis, Universiteit Utrecht, $155 \mathrm{pp}$

_ A. J. van Delden, and A. A. M. Holtslag, 1999: The inland penetration of sea breezes. Contrib. Atmos. Phys., 72, 317328.

Walsh, J. E., 1974: Sea breeze theory and applications. J. Atmos. Sci., 31, 2012-2026.

Wichink Kruit, R. J., A. A. M. Holtslag, and A. B. C. Tijm, 2004: Scaling of the sea-breeze strength with observations in the Netherlands. Bound.-Layer Meteor., 112, 369-380. 